EXPERT REVIEW

\title{
Recognizing the importance of childhood maltreatment as a critical factor in psychiatric diagnoses, treatment, research, prevention, and education
}

\author{
Martin H. Teicher (iD) ${ }^{1,2}$, Jeoffry B. Gordon (iD ${ }^{3}$ and Charles B. Nemeroff $\left(D^{4,5,6}{ }^{凶}\right.$ \\ (c) The Author(s), under exclusive licence to Springer Nature Limited 2021
}

Childhood maltreatment is the most important preventable risk factor for psychiatric disorders. Maltreated individuals typically develop psychiatric disorders at an earlier age, have a more pernicious course, more comorbidities, greater symptom severity, and respond less favorably to treatments than non-maltreated individuals with the same primary DSM-5 diagnosis. Furthermore, maltreated individuals have alterations in stress-susceptible brain regions, hypothalamic-pituitary-adrenal response, and inflammatory marker levels not discernible in their non-maltreated counterparts. Hence, maltreated and non-maltreated individuals with the same primary DSM-5 diagnoses appear to be clinically and neurobiologically distinct. The failure to embody this distinction in DSM-5 has interfered with our ability to discover novel treatments, to recommend currently available treatments most likely to be efficacious, and has been a largely unrecognized confound that has thwarted our ability to identify the biological basis for major psychiatric disorders. Incorporating this distinction into DSM will help transform this sign and symptom-based classification system to a more etiologically informed nosology. We discuss several diagnostic alternatives and recommend the inclusion of a Developmental Trauma Disorder diagnosis for severely dysregulated individuals, of all ages, with numerous comorbidities, who experienced interpersonal victimization and disruptions in attachment, such as emotional maltreatment or neglect. For less severely affected maltreated individuals, we suggest using conventional diagnostic categories, such as major depression, but with an essential modifier indicating a history of childhood maltreatment, or early life stress, to delineate the ecophenotypic variant. Implementing this strategy should improve our ability to effectively diagnose and treat individuals with psychiatric disorders and to accelerate discovery.

Molecular Psychiatry (2022) 27:1331-1338; https://doi.org/10.1038/s41380-021-01367-9

\begin{abstract}
"The first step in wisdom is to know the things themselves; this notion consists in having a true idea of the objects; objects are distinguished and known by classifying them methodically and giving them appropriate names. Therefore, classification and name-giving will be the foundation of our science."-Carolus Linnaeus
\end{abstract}

\section{INTRODUCTION}

This year, 2021, will mark a turning point in the COVID-19 pandemic. Let this year also herald a transformation in psychiatric practice, research, and education. Data supporting this shift have been growing at an exponential rate over the course of our careers and the findings are persuasive. While these discoveries are receiving increasing recognition and are being embraced by an expanding array of researchers and clinicians, many in our field remain unaware of the extent of these findings and their enormous implications. It is time for psychiatry to officially recognize these implications and to enact some essential changes.

What we will argue is that childhood abuse, childhood neglect, and other forms of childhood maltreatment (CM) or early life stress are not only the most important risk factors for many types of psychopathology, but they are critical experiential determinants that result in a cascade of molecular and neurobiological transformations that distinguish patients with maltreatment histories from their non-maltreated counterparts [1, 2]. This information is of utmost importance in treatment planning and should be a key factor in therapeutic algorithms [3]. Furthermore, the molecular and neurobiological effects of CM have been a largely unrecognized confound in psychiatric research studies and as such have been an enormous barrier to progress [4]. Recognizing the importance of CM by incorporating this information into our diagnostic nosology will enable us to better understand the epidemiology of psychiatric disorders and will help hasten the transition of the Diagnostic and Statistical Manual

\footnotetext{
'Developmental Biopsychiatry Research Program, McLean Hospital, Belmont, MA 02478, USA. ²Department of Psychiatry, Harvard Medical School, Boston, MA 02115, USA. ${ }^{3}$ Citizens Review Panel-Critical Incidents, Office of Child Abuse Prevention, California Department of Social Services, Sacramento, CA, USA. ${ }^{4}$ Institute of Early Life Adversity Research, The University of Texas at Austin, Austin, TX 78712-1873, USA. ${ }^{5}$ Mulva Clinic for the Neurosciences, The University of Texas at Austin, Austin, TX 78712-1873, USA. ${ }^{6}$ Department of Psychiatry and Behavioral Sciences, The University of Texas at Austin, Austin, TX 78712-1873, USA. ${ }^{\circledR}$ email: cnemeroff@austin.utexas.edu
} 
(DSM) [5] from an almost purely descriptive nosology into a more comprehensive classification system with an increasing focus on etiology and pathophysiology. Moreover, revising the DSM in this way will help us to provide better care for our patients and to substantially accelerate the rate and replicability of discovery.

There are several findings that we would like our colleagues to consider and understand.

\section{Prevalence}

First, CM is highly prevalent. This is especially true for individuals with psychiatric disorders. For example, Struck et al. [6] recently reported that $15.0 \%$ of adult participants with no history of psychiatric illness reported having experienced any type of moderate-to-severe CM. In contrast, 56.1\%, 56.3\%, and 57.1 of individuals with schizophrenia/schizoaffective disorder, bipolar disorder, and major depression, respectively, reported this level of exposure. This was also true of $75.4 \%$ of individuals with persistent depressive disorders [6].

\section{Risk for psychopathology}

Second, CM is the most important risk factor for many different psychiatric disorders in medically healthy individuals. It has been estimated that childhood adversity is responsible for $30 \%, 45 \%$, $54 \%, 64 \%$, and $67 \%$ of the population-attributable risk for anxiety disorders [7], childhood onset psychiatric disorders [7], depression [8], addiction to illicit drugs [9], and parenteral drug use [9], respectively. Furthermore, retrospectively reported exposure to five or more types of CM or household dysfunction increased the prospectively assessed risk of receiving an anxiolytic, antidepressant, antipsychotic, or mood stabilizer by 2.1-, 2.9-, 10.3-, and 17.3fold, respectively [10].

\section{Types of childhood maltreatment}

Third, there are many forms of CM and each, when studied independently, have been found to increase risk for psychiatric disorders [11, 12]. Furthermore, all types of maltreatment are associated with important differences in clinical presentation including: earlier onset; more severe symptoms; more pernicious course; increased risk for suicide; diminished quality of life and more psychiatric comorbidities $[1,2,11]$. When research began in earnest, 30-40 years ago, on the psychiatric consequences of CM, the focus was on sexual abuse and physical abuse as the most consequential types of CM. Recent studies that assess the psychiatric consequences of multiple types of maltreatment, including emotional abuse, emotional neglect, and physical neglect, have found that types of emotional maltreatment such as parental and peer verbal abuse are surprisingly consequential [13-15]. Verbal abuse entails insults, humiliation, threats to leave or hurt you, and proclamations such as "I wish you were never born" $[13,15,16]$. Emotional abuse and neglect have emerged in several studies as the most important risk factors for anxiety and depression [1, 6, 14, 17]. Hence, it is important to consider maltreatment broadly. In general, the more types of maltreatment reported, the greater the observed risk for psychopathology [8, 9].

A good working definition of CM has been published by the World Health Organization [18]:

"Child maltreatment is the abuse and neglect that occurs to children under 18 years of age. It includes all types of physical and/or emotional ill-treatment, sexual abuse, neglect, negligence and commercial or other exploitation, which results in actual or potential harm to the child's health, survival, development or dignity in the context of a relationship of responsibility, trust or power."

Note that a key factor in the definition is the betrayal of the child by an individual in a position of responsibility, trust, or power. This makes CM a particularly potent form of early life stress and it is CM rather than other stressors, such as natural disasters, that characteristically presents as antecedents to psychopathology [2]. This makes sense as parents, friends, and other responsible individuals can buffer the effects of stress on the developing child [19-21]. Hence, children can often endure great hardship if they feel protected and cared for. However, when the adversity is the product of their caretakers or peer group, it creates a stressor with far-reaching ramifications.

\section{Therapeutic response}

Fourth, it is critical for psychiatrists to know that patients with histories of $\mathrm{CM}$ have a poorer response to most contemporary treatment modalities than non-maltreated individuals with the same primary DSM-defined diagnosis [3, 22-24]. For example, depressed individuals with $\mathrm{CM}$ often fail to adequately respond to treatment and are at markedly increased risk for developing recurrent and persistent depressive episodes [24]. Similarly, CM has been reported to moderate response to treatment in individuals with psychotic [23], substance abuse [25], and personality disorders [26]. The association between CM and therapeutic response was explored most extensively in the international Study to Predict Optimized Treatment for Depression, which was designed to identify pretreatment predictors of response to antidepressants that could change prescribing practices. Williams et al. [3] analyzed data from the 1008 adult participants with major depressive disorder (MDD) and 336 matched healthy controls enrolled in the trial. Briefly, they found that participants with MDD had a fourfold or higher rate of exposure to childhood abuse (sexual, physical, or emotional) than healthy controls. The experience of abuse at the age of 4-7 years contributed specifically and dramatically to lack of clinical response to one of three commonly prescribed antidepressants, with only $15.9 \%$ of participants reporting abuse within this temporal vulnerability window experiencing remission versus $84.1 \%$ of participants with no abuse history. Similarly, Lewis et al. [27] in the Treatment for Adolescents with Depression Study reported that neither fluoxetine, cognitive behavioral therapy (CBT), nor their combination was more effective than placebo in teens with a history of physical abuse, and that placebo actually appeared to be more effective than CBT in teens with histories of sexual abuse. CM has also been associated with a less favorable response to CBT [28], interpersonal psychotherapy [29,30], and cognitive processing therapy [31] in adults. Interestingly, emotional abuse has often emerged as the specific type of maltreatment strongly associated with attenuated therapeutic response in a range of disorders [26, 28, 32].

In contrast, some treatments may be more effective in individuals with CM. Nemeroff et al. [22] reported that adults with chronic depression and early life stress had a more beneficial response to Cognitive Behavioral Analysis System of Psychotherapy (CBASP) than nefazadone and they appeared to have had a more favorable response to CBASP than chronically depressed individuals without early life stress. Likewise, O'Brien et al. [33] recently reported that participants with refractory depression and CM had a substantially better response to intravenous ketamine than refractory depressed individuals without $\mathrm{CM}$. More data like these are desperately needed to guide treatment and an improved classification system will facilitate and empower this essential research.

\section{Neurobiological correlates}

Fifth, CM is associated with substantial effects on brain structure, function, connectivity, and network architecture [4]. Consistent findings are smaller midsagittal area $[34,35]$ or decreased fractional anisotropy $[36,37]$ of the corpus callosum and lower hippocampal volume in adults [38, 39] but not necessarily in youths $[34,40]$. CM is also associated with attenuated development of the anterior cingulate [41-43], orbitofrontal [39, 44, 45], 
and dorsolateral prefrontal cortex [41, 45], and with enhanced amygdala response to threat $[39,46]$ and blunted striatal response to reward anticipation $[47,48]$.

Initially, researchers assumed that CM was damaging the developing brain. More likely it results in very specific phenotypic adaptations [4, 49]. This is illustrated in rigorously controlled unbiased whole brain analysis studies that assessed the structural consequences of exposure to specific types of CM. Briefly, exposure to parental verbal abuse was specifically associated with alterations in gray matter volume (GMV) in left auditory cortex [50] and with reduced integrity of the left arcuate fasciculus [51], which interconnects Broca and Wernicke's areas and is an important language pathway. Visually witnessing domestic violence, on the other hand, was specifically associated with reduced GMV in primary visual cortex [52] and reduced integrity of the inferior longitudinal fasciculus [53] that interconnects limbic and visual systems and plays an important role in our memory and emotional response to things we see. In contrast, penetrative sexual abuse was specifically associated with thinning of the portions of the somatosensory cortex in women responsible for sensation from the clitoris and surrounding genital area, while emotional abuse was associated with thinning in cortical regions relevant to self-awareness and self-evaluation [54]. In short, CM appears to result in neuroplastic adaptations that may protect a child living under abusive conditions by attenuating sensory processing of specific adverse experiences but may lead to the development of behavioral problems, such as sexual dysfunction, later in life [54].

Furthermore, there appear to be marked sex-related differences in the association between CM and brain structure, with greater reported differences in corpus callosum [55] and hippocampus [56] in maltreated males than females. There also appear to be specific sensitive periods when exposure to $\mathrm{CM}$ is associated with most significant alterations in structure [56, 57] and function [58]. For example, amygdala response to threatening visual stimuli was blunted in adults reporting exposure to physical maltreatment between ages 3-6 years but exacerbated in adults reporting exposure to peer emotional bullying at 13-15 years [58]. Again, these may be beneficial neuroplastic adaptations. A blunted fightflight response may be beneficial in young children with parents who are episodically abusive and nurturing in order to maintain the attachment bond. By teenage years an enhanced fight-flight response may be beneficial, especially in adolescents experiencing bullying. However, a blunted amygdala response, later in life, is associated with impaired recognition of dangerous situations and increased risk for substance use disorders, while an exacerbated amygdala response is associated with increased risk for anxiety and depression $[58,59]$.

\section{Maltreated versus non-maltreated subtypes}

Sixth, these CM-associated brain differences in stress-susceptible structures are present in maltreated individuals with psychiatric disorders but not necessarily in their non-maltreated counterparts $[4,60-63]$. The most extreme example of this was a study by Poletti et al. [60] in which they used voxel-based morphometry to delineate anatomical differences between 206 participants with bipolar disorder, 96 participants with schizophrenia and 136 healthy controls. Morphometric differences from controls were only discernible in the schizophrenic and bipolar participants with moderate-to-high exposure to childhood adversity and not in those with low exposure. These findings, along with marked differences in treatment response and in clinical presentation, have led us to propose that maltreated and non-maltreated individuals with the same primary DSM diagnoses are clinically and neurobiologically distinct $[2,64]$ and represent a unique ecophenotype. In addition, individuals with the CM ecophenotype appear to have an array of molecular and physiological differences. These include abnormal hypothalamic-pituitary- adrenal (HPA) axis and autonomic responses to stressors in the maltreated subtype, which are augmented in some [64] and blunted in other studies [65], likely due to differences in age as well as type and timing of exposure to CM [66]. Of critical interest is the finding that maltreated individuals with a variety of different disorders have elevated inflammatory marker levels $[1,67,68]$. Theories on the etiology of psychiatric disorders have often focused on HPA axis abnormalities and more recently on neuroinflammation, typically with no awareness that these abnormalities may be restricted to the CM subtype [69]. Furthermore, maltreatment is presumed to produce enduring biological change through an array of epigenetic modifications or by gene $\times$ experience $\times$ development interactions [1], which will also be specific to the maltreated subtype. Endeavoring to delineate the biological basis for psychiatric disorders without consideration of these critical subtype differences will almost certainly lead to conflicting results and replication failures.

\section{Neurobiology of resilience in the maltreated subtype}

Seventh, although $\mathrm{CM}$ is a potent risk factor for many different psychiatric disorders there are a substantial number of individuals with CM histories who appear to be relatively resilient. We are referring to resilience here in a medical sense as absence of pathology or "better than expected outcome" following exposure to a potent risk factor [70]. Logically one might expect that the brains of these resilient individuals would show little if any of the aforementioned alterations in stress-susceptible regions or pathways. However, the whole complement of maltreatmentassociated brain changes have been reported in maltreated individuals without overt psychopathology $[4,71]$. This has led us, and others, to propose that asymptomatic MAL individuals are not unaffected but are effectively compensating through other neurobiological mechanisms [4, 71-74]. Ohashi et al. [75] reported that symptomatic and asymptomatic maltreated individuals had the same constellation of global brain network abnormalities, but the asymptomatic group could be reliably distinguished from the symptomatic maltreated group, and from unexposed controls, based on the connectivity of nine specific brain regions. This is an intriguing observation as it suggests that effective treatments for psychiatric disorders in individuals with $\mathrm{CM}$ may not require reversing the neurobiological effects of $\mathrm{CM}$ but may occur through altering connectivity in specific brain regions to bring the nodal network architecture of susceptible individuals into line with that of their more resilient counterparts [75, 76]. Of considerable interest is whether these are preexisting neurobiological differences that protect individuals from the psychiatric consequences of $\mathrm{CM}$, or if they emerge over the course of time, and how they may be affected by protective factors and compensatory remedial environmental experiences [77, 78]. Overall, these findings indicate that moderate-to-severe $\mathrm{CM}$ is a transformative rather than normative event in even the relatively small percent of individual without psychiatric disorders who report this degree of exposure.

\section{IMPLICATIONS}

There are five critical implications from these discoveries that we will enumerate and then discuss further below. First, it is essential that clinicians obtain a maltreatment history when assessing or treating individuals with psychiatric disorders. Because maltreatment is also a major risk factor for a host of medical disorders including cancer as well as heart, liver, digestive, and respiratory disease [79-81], one can argue that a maltreatment history should be an essential part of everyone's medical history. Second, as maltreated and non-maltreated cohorts with psychiatric disorders are so vastly different, this needs to be fully incorporated into our diagnostic nosology, preferably with a specific code to delineate the CM-associated ecophenotype. Third, we urge all investigators 
conducting treatment trials for psychiatric disorders to collect data on $\mathrm{CM}$ and to analyze the data to indicate the extent to which CM moderates response. Perhaps the most effective way to do this would be for psychiatry and clinical psychology journals to strongly advocate this practice. Similarly, epidemiology and genetic risk studies would also benefit from inclusion of CM as a key biological variable. Fourth, clinical research studies on the biological basis of psychiatric disorders should, in almost all instances, collect data on $\mathrm{CM}$ as a key biological variable. Researchers would not consider conducting a study without controlling for the influence of sex or psychiatric medications. In general, maltreatment is a much more powerful confounding factor. Again, journals should take the lead in advocating this position along with the $\mathrm{NIH}$. There may be situations when doing so would not be feasible (e.g., public datasets or autopsy samples without this information) and this should be noted in publications as a significant limitation. Fifth, as maltreatment is such a potent risk factor there should be a concerted effort to reduce exposure and a major effort to develop strategies to preempt the emergence of psychiatric disorders in youths who have been exposed. We encourage the NIMH, NIDA, NIAAA, and NICHD to make these high priority areas and for the field to place much more emphasis on prevention and preemption.

These recommendations may seem burdensome to researchers and clinicians who are unfamiliar with collecting and utilizing this information. Adequate data on exposure to maltreatment can be collected in a matter of minutes using any of a number of validated instruments with high test-retest reliability, such as the short form of the Childhood Trauma Questionnaire [82] or the Adverse Childhood Experiences scale (https://acestoohigh.com/ got-your-ace-score/). We have included recommendations for researchers $(\mathrm{S} 1, \mathrm{~S} 2)$ and for clinicians $(\mathrm{S} 3, \mathrm{~S} 4)$ in the Supplementary materials on how to collect this information and how to incorporate it into their data analyses and clinical practice.

The absence of required specifiers for $\mathrm{CM}$ in the current formulation of the DSM distorts and impairs the value of many contemporary studies on the neurobiology, epidemiology, and treatment of psychiatric disorders. For example, a recently published [83], comprehensive analysis of risk factors for suicides in juveniles included over 7000 children and 910 suicides. Data were obtained from death certificates and Medicaid billing files. Although the ICD systems used to bill and indicate diagnoses have codes for exposure to child abuse (e.g., ICD-9CM 995.50-995.59; ICD-10CM T74.1-T74.9, and Z61.4-Z61.6), treating practitioners routinely use only ICD-9 and ICD-10 codes consistent with DSM-5 when evaluating and billing their patients. Based on the records used, this study found that youth suicide was most prominently associated with DSM-5 diagnoses of schizophrenia, depression, bipolar disorder, and substance use. However, most of the suicide decedents in the study did not have a recorded mental health diagnosis. Unfortunately, given this coding limitation, little was known about their exposure to $\mathrm{CM}$ and this factor was not mentioned, considered, or discussed in this study. This is a serious limitation that could markedly affect the analysis and interpretation of results as it has been reported that CM and household dysfunction account for up to $80 \%$ of the population-attributable risk for suicide attempts during childhood or adolescence [84]. Hence, we do not know if schizophrenia, depression, bipolar disorder, and substance abuse emerged as key risk factors because of the nature of the underlying disorder, or because of the very high prevalence of maltreatment within these diagnostic categories [6]. We can only know this by comparing incident rates in maltreated versus non-maltreated youths with these diagnoses. Knowledge of prior or ongoing CM would not only be important in studying the causes and epidemiology of youth suicide, it would be most useful in the clinic and among the most actionable considerations in the prevention of youth suicide if it emerges as a critical independent risk factor.
Another example is a recent paper on conceptual models and risk factors for treatment-resistant depression (TRD) [85]. A variety of potential biological factors were discussed in the article including activation of the inflammatory system, HPA axis disturbance, dysfunctional neuroanatomic circuits such as the default mode network, abnormal neural activity, and neurotransmitter dysfunction. Although abuse was briefly mentioned as a risk factor for TRD, there was no apparent understanding that CM may produce all of the aforementioned biological risk factors (e.g., inflammation $[1,67,68]$, HPA axis disturbance [64, 86], dysfunctional neuroanatomic circuits $[4,87]$, abnormal neural activity [8891], and neurotransmitter dysfunction [92-94]) as well as a host of critical clinical risk factors such as inadequate response to antidepressants [3]. Hence, the authors missed the opportunity to present a unified and parsimonious conceptual model for TRD.

\section{NOSOLOGICAL MODIFICATIONS}

The thorniest question is how to modify psychiatric nosology. The need however is clear given the critically important clinical, molecular, and neurobiological differences between maltreated and non-maltreated individuals with the same primary diagnosis and the benefits of having information on exposure for epidemiological and clinical research purposes. Unfortunately, DSM-5 relegates CM to a brief section at the back of the volume (1, p. $715 \mathrm{ff})$ under "Other Conditions That May Be the Focus of Clinical Attention" as an environmental condition, specifically "not (a) mental disorder" (and thus cannot be used for billing) and which "may be included in the medical record as useful information on circumstances that may affect the patient's care." Consequently, these codes are rarely utilized. ICD codes do have specific and well-defined CM categories, but because, at least in the USA, clinical records must be coded for billing using DSM diagnoses, it is not possible in epidemiologic studies using billing data to reliably translate less-detailed DSM-defined billing codes into more specific ICD diagnostic categories when $C M$ is a consideration.

Post-traumatic stress disorder (PTSD) is often applied as a diagnostic label to individuals with mental illness secondary to $\mathrm{CM}$, but the criteria actually required for a PTSD diagnosis are not met by most victims of CM. For example, Famularo et al. [95] found that only $35 \%$ of severely maltreated and psychologically traumatized children who were removed from parental custody due to the trauma actually met strict criteria for PTSD. This is not necessarily a matter of resilience. Kiser et al. [96] found that maltreated children and adolescents with psychiatric problems who did not meet criteria for PTSD actually exhibited more anxiety, depression, externalizing behaviors, and more overall problems than children who did. Similarly, psychiatrically hospitalized youth with CM but without PTSD were found to have more disrupted sleep than youth meeting criteria for PTSD [97]. Furthermore, they also responded more poorly to psychotherapy than traumatized youth meeting full criteria for PTSD [98]. These findings suggest that PTSD criteria formulated and validated in adults do not adequately describe the psychiatric impact of exposure to $\mathrm{CM}$, and do not necessarily identify children most adversely affected by trauma let alone by other forms of maltreatment that do not fit the DSM definition of trauma. Furthermore, although some maltreated individuals do meet criteria for PTSD, this diagnostic coding does not indicate the existence of a CM history critical for research or epidemiologic purposes.

Similarly, a relatively small percentage of individuals with CM and severe psychopathology will meet criteria for complex PTSD (CPTSD), which has now been recognized as a distinct diagnostic category in ICD-11. Key criteria include the three PTSD requirements of reexperiencing, avoidance, and hypervigilance, as well as three disturbances in self-organization characterized by emotional 
dysregulation, interpersonal difficulties, and negative self-concept. This diagnosis was formulated to capture the more complex clinical consequences of exposure to prolonged and extreme adversity, as seen in victims of persistent childhood sexual abuse, child soldiering, severe domestic violence, torture, genocide campaigns, or slavery [99]. While some individuals with CM histories will meet criteria for CPTSD, it is likely that individuals who experienced extreme adversity during childhood will have a different array of molecular and neurobiological alterations than individuals who have experienced extreme adversity in adulthood and these groups may well respond differently to treatment. Hence, neither PTSD nor CPTSD provide the clarity that a comprehensive nosology requires.

A more maltreatment-centric possibility is Developmental Trauma Disorder (DTD), which has been proposed as a diagnostic category for youths who have experienced CM and other forms of childhood adversity and who experience dysregulation in three spheres-emotional/somatic, attentional/behavioral, and relational/self-identity [100]. This proposed diagnosis is structured like PTSD with a requisite criterion A exposure but unlike PTSD (which focuses on threat of death, serious injury, or sexual violence), it requires both interpersonal victimization (physical or sexual assault, witnessing domestic violence) and disrupted attachment with a primary caregiver (prolonged separation, neglect, emotional abuse). In general, youths who meet criteria for this proposed disorder experienced poly-victimization have an average of 5.3 different DSM diagnoses on structured interview and have very high scores for dysregulation as well as externalizing and internalizing symptoms on the Child Behavioral Checklist [100]. In short, DTD identifies a relatively small but seriously impaired subset of youths with CM and psychopathology. This is an appealing unitary diagnostic category and the failure to include it in DSM-5 should be rectified.

The need for a unitary diagnostic label for maltreated youths with severe mental health problems, and the inadequacies of current DSM classification, were highlighted in a recent report issued by key committees from the American Academy of Pediatrics and the American Academy of Child and Adolescent Psychiatry [101]. They used the term "complex trauma" to describe the effects of exposure during childhood to multiple or chronic traumatic events, or to severe, pervasive, or prolonged maltreatment, which result in a wide range of behavioral, cognitive, and emotional alterations that do not fit easily into common diagnostic categories and require a "thoughtful and parsimonious formulations rather than a laundry list of diagnoses." This report also notes that abnormal "behaviors...in the presence of ongoing danger are not pathologic but a normal stress response" and "there is little value in a pharmacotherapy trial for possible comorbidities until the danger has been mitigated." In short, approaching behavior problems in youth from within the current DSM paradigm can lead to inattention to ongoing CM and misguided attempts at medication management.

Unfortunately, there is a trend to label youths exposed to "complex trauma" with DTD and to label adults with the same childhood exposure with CPTSD. This makes little sense as the actual diagnostic criteria proposed for these two disorders are distinctly different. We believe that it would make more sense clinically and neurobiologically to have one diagnostic category, such as DTD, for individuals who experienced "complex trauma" during childhood (with or without adult exposure) and another diagnostic category, such as CPTSD, for individuals who experienced "complex trauma" during adulthood but not childhood.

Most individuals with CM and psychopathology, however, will not meet criteria for DTD. Some of these individuals will have experienced DTD criterion A exposure but will not manifest the three required forms of dysregulation, or they may have experienced only one part of the criterion A exposure, such as emotional abuse. Maltreated individuals who do not meet DTD criteria will typically have fewer DSM diagnoses and may have less severe psychopathology than those with DTD [100]. Major depression with a comorbid anxiety disorder, or substance use disorders, or bipolar disorder is typical clinical presentation of maltreated individuals who do not meet DTD criteria. For these individuals we recommended, as a first step, a moderate revision to the DSM, to add the specifier "With Maltreatment History" or "With Early Life Stress" to their primary DSM diagnosis to recognize that these individuals are part of a distinct maltreatment-related subtype or ecophenotype $[2,64]$.

\section{CONCLUSIONS}

DSM-5, as we are well aware, is a work in progress and that a medical classification system that focuses entirely on signs and symptoms without regard to etiology, pathophysiology, or theory will misconstrue pathophysiologically heterogeneous disorders with similar clinical presentations as unitary, and unitary disorders that can present in distinctly different ways as heterogeneous [102]. Revising the DSM to acknowledge the critical role of CM would be a quantum step forward in the development of an etiologically informed classification system. Indeed, we predict that recognizing $\mathrm{CM}$ as an etiological agent that can produce ecophenotypic variants of major psychiatric disorders or DTD may prove to be as pivotal for psychiatry as germ theory has been for internal medicine. At the very least this will provide an opportunity to explore the common phenomenon that patients who have been abused respond poorly to standard pharmacologic and psychotherapeutic treatment and allow a more expansive exploration of treatments specific for the sequelae of CM. In addition, being able to specifically diagnose patients with post $\mathrm{CM}$ disorders will facilitate identification of the complimentary stateresilience-and catalyze more research into that phenomenon. Heightened attention to CM-associated diagnoses will also better inform public policy and needs to be a critical component in the education and training of mental health professionals.

\section{REFERENCES}

1. Lippard ETC, Nemeroff CB. The devastating clinical consequences of child abuse and neglect: increased disease vulnerability and poor treatment response in mood disorders. Am J Psychiatry. 2020;177:20-36.

2. Teicher MH, Samson JA. Childhood maltreatment and psychopathology: a case for ecophenotypic variants as clinically and neurobiologically distinct subtypes. Am J Psychiatry. 2013;170:1114-33.

3. Williams LM, Debattista C, Duchemin AM, Schatzberg AF, Nemeroff CB. Childhood trauma predicts antidepressant response in adults with major depression: data from the randomized international Study to Predict Optimized Treatment for Depression. Transl Psychiatry. 2016;6:e799.

4. Teicher MH, Samson JA, Anderson CM, Ohashi K. The effects of childhood maltreatment on brain structure, function and connectivity. Nat Rev Neurosci. 2016;17:652-66.

5. American Psychiatric Association. Diagnostic and Statistical Manual of mental disorders. 5th ed. Washington DC: American Psychiatric Press; 2013.

6. Struck N, Krug A, Yuksel D, Stein F, Schmitt S, Meller T, et al. Childhood maltreatment and adult mental disorders-the prevalence of different types of maltreatment and associations with age of onset and severity of symptoms. Psychiatry Res. 2020;293:113398.

7. Green JG, McLaughlin KA, Berglund PA, Gruber MJ, Sampson NA, Zaslavsky AM, et al. Childhood adversities and adult psychiatric disorders in the national comorbidity survey replication I: associations with first onset of DSM-IV disorders. Arch Gen Psychiatry. 2010;67:113-23.

8. Dube SR, Felitti VJ, Dong M, Giles WH, Anda RF. The impact of adverse childhood experiences on health problems: evidence from four birth cohorts dating back to 1900. Prev Med. 2003;37:268-77.

9. Dube SR, Felitti VJ, Dong M, Chapman DP, Giles WH, Anda RF. Childhood abuse, neglect, and household dysfunction and the risk of illicit drug use: the adverse childhood experiences study. Pediatrics. 2003;111:564-72.

10. Anda RF, Brown DW, Felitti VJ, Bremner JD, Dube SR, Giles WH. Adverse childhood experiences and prescribed psychotropic medications in adults. Am J Prev Med. 2007;32:389-94. 
11. Medeiros GC, Prueitt WL, Minhajuddin A, Patel SS, Czysz AH, Furman JL, et al. Childhood maltreatment and impact on clinical features of major depression in adults. Psychiatry Res. 2020;293:113412.

12. Norman RE, Byambaa M, De R, Butchart A, Scott J, Vos T. The long-term health consequences of child physical abuse, emotional abuse, and neglect: a systematic review and meta-analysis. PLoS Med. 2012;9:e1001349.

13. Teicher MH, Samson JA, Polcari A, McGreenery CE. Sticks, stones, and hurtful words: relative effects of various forms of childhood maltreatment. Am J Psychiatry. 2006;163:993-1000.

14. Khan A, McCormack HC, Bolger EA, McGreenery CE, Vitaliano G, Polcari A, et al. Childhood maltreatment, depression, and suicidal ideation: critical importance of parental and peer emotional abuse during developmental sensitive periods in males and females. Front Psychiatry. 2015;6:42.

15. Teicher MH, Samson JA, Sheu YS, Polcari A, McGreenery CE. Hurtful words: association of exposure to peer verbal abuse with elevated psychiatric symptom scores and corpus callosum abnormalities. Am J Psychiatry. 2010;167:1464-71.

16. Teicher $\mathrm{MH}$, Parigger A. The 'Maltreatment and Abuse Chronology of Exposure' (MACE) scale for the retrospective assessment of abuse and neglect during development. PLoS One. 2015;10:e0117423.

17. Humphreys KL, LeMoult J, Wear JG, Piersiak HA, Lee A, Gotlib IH. Child maltreatment and depression: a meta-analysis of studies using the Childhood Trauma Questionnaire. Child Abus Negl. 2020;102:104361.

18. World Health Organization. WHO Guidelines for the health sector response to child maltreatment. Technical Report. Geneva: WHO; 2019.

19. Forster M, Gower AL, Borowsky IW, McMorris BJ. Associations between adverse childhood experiences, student-teacher relationships, and non-medical use of prescription medications among adolescents. Addict Behav. 2017;68:30-34.

20. Howell BR, McMurray MS, Guzman DB, Nair G, Shi Y, McCormack KM, et al. Maternal buffering beyond glucocorticoids: impact of early life stress on corticolimbic circuits that control infant responses to novelty. Soc Neurosci. 2017; 12:50-64.

21. Powers A, Ressler KJ, Bradley RG. The protective role of friendship on the effects of childhood abuse and depression. Depress Anxiety. 2009;26:46-53.

22. Nemeroff CB, Heim CM, Thase ME, Klein DN, Rush AJ, Schatzberg AF, et al. Differential responses to psychotherapy versus pharmacotherapy in patients with chronic forms of major depression and childhood trauma. Proc Natl Acad Sci USA. 2003;100:14293-6.

23. Thomas S, Hofler M, Schafer I, Trautmann S. Childhood maltreatment and treatment outcome in psychotic disorders: a systematic review and metaanalysis. Acta Psychiatr Scand. 2019;140:295-312.

24. Nanni V, Uher R, Danese A. Childhood maltreatment predicts unfavorable course of illness and treatment outcome in depression: a meta-analysis. Am J Psychiatry. 2012;169:141-51.

25. Schuckher F, Sellin T, Engstrom I, Berglund K. History of childhood abuse is associated with less positive treatment outcomes in socially stable women with alcohol use disorder. BMC Women's Health. 2019;19:159.

26. Euler S, Stalujanis E, Lindenmeyer HJ, Nicastro R, Kramer U, Perroud N, et al. Impact of childhood maltreatment in borderline personality disorder on treatment response to intensive dialectical behavior therapy. J Pers Disord. 2021;35:428-46.

27. Lewis CC, Simons AD, Nguyen LJ, Murakami JL, Reid MW, Silva SG, et al. Impact of childhood trauma on treatment outcome in the Treatment for Adolescents with Depression Study (TADS). J Am Acad Child Adolesc Psychiatry. 2010;49:132-40.

28. Ammerman RT, Peugh JL, Teeters AR, Putnam FW, Van Ginkel JB. Child maltreatment history and response to CBT treatment in depressed mothers participating in home visiting. J Interpers Violence. 2016;31:774-91.

29. Harkness KL, Bagby RM, Kennedy SH. Childhood maltreatment and differential treatment response and recurrence in adult major depressive disorder. J Consult Clin Psychol. 2012;80:342-53.

30. Grote NK, Spieker SJ, Lohr MJ, Geibel SL, Swartz HA, Frank E, et al. Impact of childhood trauma on the outcomes of a perinatal depression trial. Depress Anxiety. 2012;29:563-73.

31. Bosch J, Mackintosh MA, Wells SY, Wickramasinghe I, Glassman LH, Morland LA. PTSD treatment response and quality of life in women with childhood trauma histories. Psychol Trauma. 2020;12:55-63.

32. Misiak B, Frydecka D. A history of childhood trauma and response to treatment with antipsychotics in first-episode schizophrenia patients: preliminary results. J Nerv Ment Dis. 2016;204:787-92.

33. O'Brien B, Lijfijt M, Wells A, Swann AC, Mathew SJ. The impact of childhood maltreatment on intravenous ketamine outcomes for adult patients with treatment-resistant depression. Pharmaceuticals (Basel). 2019;12:133.

34. De Bellis MD, Keshavan MS, Shifflett $H$, lyengar $S$, Beers SR, Hall J, et al. Brain structures in pediatric maltreatment-related posttraumatic stress disorder: a sociodemographically matched study. Biol Psychiatry. 2002;52:1066-78.
35. Teicher MH, Dumont NL, Ito Y, Vaituzis C, Giedd JN, Andersen SL. Childhood neglect is associated with reduced corpus callosum area. Biol Psychiatry. 2004; $56: 80-85$

36. Jackowski AP, Douglas-Palumberi $H$, Jackowski M, Win L, Schultz RT, Staib LW, et al. Corpus callosum in maltreated children with posttraumatic stress disorder: a diffusion tensor imaging study. Psychiatry Res. 2008;162:256-61.

37. McCarthy-Jones S, Oestreich LKL, Lyall AE, Kikinis Z, Newell DT, Savadjiev $P$, et al. Childhood adversity associated with white matter alteration in the corpus callosum, corona radiata, and uncinate fasciculus of psychiatrically healthy adults. Brain Imaging Behav. 2018;12:449-58.

38. Teicher $\mathrm{MH}$, Anderson $\mathrm{CM}$, Polcari A. Childhood maltreatment is associated with reduced volume in the hippocampal subfields $C A 3$, dentate gyrus, and subiculum. Proc Natl Acad Sci USA. 2012;109:E563-72.

39. Dannlowski U, Stuhrmann A, Beutelmann V, Zwanzger P, Lenzen T, Grotegerd D, et al. Limbic scars: long-term consequences of childhood maltreatment revealed by functional and structural magnetic resonance imaging. Biol Psychiatry. 2012;71:286-93.

40. Woon FL, Hedges DW. Hippocampal and amygdala volumes in children and adults with childhood maltreatment-related posttraumatic stress disorder: a meta-analysis. Hippocampus. 2008;18:729-36.

41. Tomoda A, Suzuki H, Rabi K, Sheu YS, Polcari A, Teicher MH. Reduced prefrontal cortical gray matter volume in young adults exposed to harsh corporal punishment. Neuroimage. 2009;47(Suppl 2):T66-71.

42. Cohen RA, Grieve S, Hoth KF, Paul RH, Sweet L, Tate D, et al. Early life stress and morphometry of the adult anterior cingulate cortex and caudate nuclei. Biol Psychiatry. 2006:59:975-82.

43. Jensen SK, Dickie EW, Schwartz DH, Evans CJ, Dumontheil I, Paus T, et al. Effect of early adversity and childhood internalizing symptoms on brain structure in young men. JAMA Pediatr. 2015;169:938-46.

44. Hanson JL, Chung MK, Avants BB, Shirtcliff EA, Gee JC, Davidson RJ, et al. Early stress is associated with alterations in the orbitofrontal cortex: a tensor-based morphometry investigation of brain structure and behavioral risk. J Neurosci. 2010;30:7466-72.

45. Edmiston EE, Wang F, Mazure CM, Guiney J, Sinha R, Mayes LC, et al. Corticostriatal-limbic gray matter morphology in adolescents with self-reported exposure to childhood maltreatment. Arch Pediatr Adolesc Med. 2011;165:1069-77.

46. McLaughlin KA, Peverill M, Gold AL, Alves S, Sheridan MA. Child maltreatment and neural systems underlying emotion regulation. J Am Acad Child Adolesc Psychiatry. 2015;54:753-62.

47. Boecker R, Holz NE, Buchmann AF, Blomeyer D, Plichta MM, Wolf I, et al. Impact of early life adversity on reward processing in young adults: EEG-fMRI results from a prospective study over 25 years. PLoS One. 2014;9:e104185.

48. Novick AM, Levandowski ML, Laumann LE, Philip NS, Price LH, Tyrka AR. The effects of early life stress on reward processing. J Psychiatr Res. 2018;101:80-103.

49. Teicher MH. Scars that won't heal: the neurobiology of child abuse. Sci Am. 2002;286:68-75.

50. Tomoda A, Sheu YS, Rabi K, Suzuki H, Navalta CP, Polcari A. et al. Exposure to parental verbal abuse is associated with increased gray matter volume in superior temporal gyrus. Neuroimage. 2011;54(Suppl 1):S280-6.

51. Choi J, Jeong B, Rohan ML, Polcari AM, Teicher MH. Preliminary evidence for white matter tract abnormalities in young adults exposed to parental verbal abuse. Biol Psychiatry. 2009;65:227-34

52. Tomoda A, Polcari A, Anderson CM, Teicher MH. Reduced visual cortex gray matter volume and thickness in young adults who witnessed domestic violence during childhood. PLoS One. 2012;7:e52528.

53. Choi J, Jeong B, Polcari A, Rohan ML, Teicher MH. Reduced fractional anisotropy in the visual limbic pathway of young adults witnessing domestic violence in childhood. Neuroimage. 2012;59:1071-9.

54. Heim CM, Mayberg HS, Mletzko T, Nemeroff CB, Pruessner JC. Decreased cortical representation of genital somatosensory field after childhood sexual abuse. Am J Psychiatry. 2013;170:616-23.

55. De Bellis MD, Keshavan MS, Clark DB, Casey BJ, Giedd JN, Boring AM. et al. A.E. Bennett Research Award. Developmental traumatology. Part II: brain development. Biol Psychiatry. 1999;45:1271-84.

56. Teicher MH, Anderson CM, Ohashi K, Khan A, McGreenery CE, Bolger EA, et al. Differential effects of childhood neglect and abuse during sensitive exposure periods on male and female hippocampus. Neuroimage. 2018;169:443-52.

57. Herzog Jl, Thome J, Demirakca T, Koppe G, Ende G, Lis S, et al. Influence of severity of type and timing of retrospectively reported childhood maltreatment on female amygdala and hippocampal volume. Sci Rep. 2020;10:1903.

58. Zhu J, Lowen SB, Anderson CM, Ohashi K, Khan A, Teicher MH. Association of prepubertal and postpubertal exposure to childhood maltreatment with adult amygdala function. JAMA Psychiatry. 2019;76:843-53. 
59. Mujica-Parodi LR, Cha J, Gao J. From anxious to reckless: a control systems approach unifies prefrontal-limbic regulation across the spectrum of threat detection. Front Syst Neurosci. 2017;11:18.

60. Poletti S, Vai B, Smeraldi E, Cavallaro R, Colombo C, Benedetti F. Adverse childhood experiences influence the detrimental effect of bipolar disorder and schizophrenia on cortico-limbic grey matter volumes. J Affect Disord. 2016;189:290-7.

61. Vythilingam M, Heim C, Newport J, Miller AH, Anderson E, Bronen R, et al. Childhood trauma associated with smaller hippocampal volume in women with major depression. Am J Psychiatry. 2002;159:2072-80.

62. Opel N, Redlich R, Zwanzger P, Grotegerd D, Arolt V, Heindel W, et al. Hippocampal atrophy in major depression: a function of childhood maltreatment rather than diagnosis? Neuropsychopharmacology. 2014;39:2723-31.

63. Chaney A, Carballedo A, Amico F, Fagan A, Skokauskas N, Meaney J, et al. Effect of childhood maltreatment on brain structure in adult patients with major depressive disorder and healthy participants. J Psychiatry Neurosci. 2014;39:50-59.

64. Heim C, Newport DJ, Mletzko T, Miller AH, Nemeroff CB. The link between childhood trauma and depression: insights from HPA axis studies in humans. Psychoneuroendocrinology. 2008;33:693-710.

65. Carpenter LL, Shattuck TT, Tyrka AR, Geracioti TD, Price LH. Effect of childhood physical abuse on cortisol stress response. Psychopharmacology (Berl). 2011;214:367-75.

66. Tarullo AR, Gunnar MR. Child maltreatment and the developing HPA axis. Horm Behav. 2006;50:632-9.

67. Baldwin JR, Arseneault L, Caspi A, Fisher $\mathrm{HL}$, Moffitt $T E$, Odgers $C L$, et al. Childhood victimization and inflammation in young adulthood: a genetically sensitive cohort study. Brain Behav Immun. 2018;67:211-7.

68. Danese A, Moffitt TE, Pariante CM, Ambler A, Poulton R, Caspi A. Elevated inflammation levels in depressed adults with a history of childhood maltreatment. Arch Gen Psychiatry. 2008;65:409-15.

69. Danese A, Moffitt TE, Harrington H, Milne BJ, Polanczyk G, Pariante CM, et al. Adverse childhood experiences and adult risk factors for age-related disease: depression, inflammation, and clustering of metabolic risk markers. Arch Pediatr Adolesc Med. 2009;163:1135-43.

70. Luthar SS, Cicchetti D, Becker B. The construct of resilience: a critical evaluation and guidelines for future work. Child Dev. 2000;71:543-62.

71. Teicher MH, Samson JA. Annual research review: enduring neurobiological effects of childhood abuse and neglect. J Child Psychol Psychiatry. 2016;57:241-66.

72. Hanson JL, Knodt AR, Brigidi BD, Hariri AR. Lower structural integrity of the uncinate fasciculus is associated with a history of child maltreatment and future psychological vulnerability to stress. Dev Psychopathol. 2015;27:1611-9.

73. Sun D, Haswell CC, Morey RA, De Bellis MD. Brain structural covariance network centrality in maltreated youth with PTSD and in maltreated youth resilient to PTSD. Dev Psychopathol. 2019:31:557-71.

74. Cisler JM, Herringa RJ. Posttraumatic stress disorder and the developing adolescent brain. Biol Psychiatry. 2021;89:144-51.

75. Ohashi K, Anderson CM, Bolger EA, Khan A, McGreenery CE, Teicher MH. Susceptibility or resilience to maltreatment can be explained by specific differences in brain network architecture. Biol Psychiatry. 2019;85:690-702.

76. Teicher $\mathrm{MH}$, Ohashi $\mathrm{K}$, Khan A. Additional insights into the relationship between brain network architecture and susceptibility and resilience to the psychiatric sequelae of childhood maltreatment. Advers Resil Sci. 2020;1:49-64.

77. Werner EE. Risk, resilience, and recovery: perspectives from the Kauai Longitudinal Study. Dev Psychopathol. 1993;5:503-15.

78. Denckla CA, Cicchetti D, Kubzansky LD, Seedat S, Teicher MH, Williams DR, et al. Psychological resilience: an update on definitions, a critical appraisal, and research recommendations. Eur J Psychotraumatol. 2020;11:1822064.

79. Hughes K, Bellis MA, Hardcastle KA, Sethi D, Butchart A, Mikton C, et al. The effect of multiple adverse childhood experiences on health: a systematic review and meta-analysis. Lancet Public Health. 2017;2:e356-66.

80. Felitti VJ, Anda RF, Nordenberg D, Williamson DF, Spitz AM, Edwards V, et al. Relationship of childhood abuse and household dysfunction to many of the leading causes of death in adults. The Adverse Childhood Experiences (ACE) Study. Am J Prev Med. 1998;14:245-58.

81. Merrick MT, Ford DC, Ports KA, Guinn AS, Chen J, Klevens J, et al. Vital signs: estimated proportion of adult health problems attributable to adverse childhood experiences and implications for prevention - 25 states, 2015-7. MMWR Morb Mortal Wkly Rep. 2019;68:999-1005.

82. Bernstein DP, Stein JA, Newcomb MD, Walker E, Pogge D, Ahluvalia T, et al. Development and validation of a brief screening version of the Childhood Trauma Questionnaire. Child Abus Negl. 2003;27:169-90.
83. Fontanella CA, Warner LA, Steelesmith D, Bridge JA, Sweeney HA, Campo JV. Clinical profiles and health services patterns of medicaid-enrolled youths who died by suicide. JAMA Pediatr. 2020;174:470-7.

84. Dube SR, Anda RF, Felitti VJ, Chapman DP, Williamson DF, Giles WH. Childhood abuse, household dysfunction, and the risk of attempted suicide throughout the life span: findings from the Adverse Childhood Experiences Study. JAMA. 2001;286:3089-96.

85. Murphy JA, Sarris J, Byrne GJ. A review of the conceptualisation and risk factors associated with treatment-resistant depression. Depress Res Treat. 2017;2017:4176825.

86. Shea A, Walsh C, Macmillan H, Steiner M. Child maltreatment and HPA axis dysregulation: relationship to major depressive disorder and post traumatic stress disorder in females. Psychoneuroendocrinology. 2005;30:162-78.

87. Tozzi L, Garczarek L, Janowitz D, Stein DJ, Wittfeld K, Dobrowolny H, et al. Interactive impact of childhood maltreatment, depression, and age on cortical brain structure: mega-analytic findings from a large multi-site cohort. Psychol Med. 2020;50:1020-31.

88. Ito $\mathrm{Y}$, Teicher MH, Glod CA, Harper D, Magnus E, Gelbard HA. Increased prevalence of electrophysiological abnormalities in children with psychological, physical, and sexual abuse. J Neuropsychiatry Clin Neurosci. 1993;5:401-8.

89. Miskovic V, Schmidt LA, Georgiades K, Boyle M, Macmillan HL. Adolescent females exposed to child maltreatment exhibit atypical EEG coherence and psychiatric impairment: linking early adversity, the brain, and psychopathology. Dev Psychopathol. 2010;22:419-32.

90. Bader K, Schafer V, Nissen L, Schenkel M. Heightened beta EEG activity during nonrapid eye movement sleep in primary insomnia patients with reports of childhood maltreatment. J Clin Neurophysiol. 2013;30:188-98.

91. Meiers G, Nooner K, De Bellis MD, Debnath R, Tang A. Alpha EEG asymmetry, childhood maltreatment, and problem behaviors: a pilot home-based study. Child Abus Negl. 2020;101:104358.

92. Berglund KJ, Balldin J, Berggren U, Gerdner A, Fahlke C. Childhood maltreatment affects the serotonergic system in male alcohol-dependent individuals. Alcohol Clin Exp Res. 2013;37:757-62.

93. Shrivastava AK, Karia SB, Sonavane SS, De Sousa AA. Child sexual abuse and the development of psychiatric disorders: a neurobiological trajectory of pathogenesis. Ind Psychiatry J. 2017;26:4-12.

94. Egerton A, Valmaggia LR, Howes OD, Day F, Chaddock CA, Allen $P$, et al. Adversity in childhood linked to elevated striatal dopamine function in adulthood. Schizophr Res. 2016;176:171-6.

95. Famularo R, Fenton T, Kinscherff R. Child maltreatment and the development of posttraumatic stress disorder. Am J Dis Child. 1993;147:755-60.

96. Kiser L, Heston J, Millsap PA, Pruitt DB. Physical and sexual abuse in childhood: relationship with post-traumatic stress disorder. J Am Acad Child Adolesc Psychiatry. 1991;30:776-83.

97. Glod CA, Teicher MH, Hartman CR, Harakal T. Increased nocturnal activity and impaired sleep maintenance in abused children. J Am Acad Child Adolesc Psychiatry. 1997;36:1236-43.

98. Gillies D, Maiocchi L, Bhandari AP, Taylor F, Gray C, O'Brien L. Psychological therapies for children and adolescents exposed to trauma. Cochrane Database Syst Rev. 2016;10:CD012371.

99. Cloitre M, Garvert DW, Brewin CR, Bryant RA, Maercker A. Evidence for proposed ICD-11 PTSD and complex PTSD: a latent profile analysis. Eur J Psychotraumatol. 2013;4.

100. Ford JD, Spinazzola J, van der Kolk B, Grasso DJ. Toward an empirically based developmental trauma disorder diagnosis for children: factor structure, item characteristics, reliability, and validity of the developmental trauma disorder semi-structured interview. J Clin Psychiatry. 2018;79:17m11675.

101. Keeshin B, Forkey HC, Fouras G, MacMillan HL, American Academy of Pediatrics Council on Child Abuse and Neglect, Council on Foster Care, Adoption, and Kinship Care; American Academy of Child and Adolescent Psychiatry Committee on Child Maltreatment and Violence, et al. Children exposed to maltreatment: assessment and the role of psychotropic medication. Pediatrics. 2020;145: e20193751.

102. Insel T, Cuthbert B, Garvey M, Heinssen R, Pine DS, Quinn K, et al. Research domain criteria (RDoC): toward a new classification framework for research on mental disorders. Am J Psychiatry. 2010;167:748-51.

\section{ACKNOWLEDGEMENTS}

We thank Kelly Puzdrak for technical assistance. Sources of support include NIH RO1 awards HD-079484 (MHT), DA-017846 (MHT), MH-117293 (CBN), AA-024933 (CBN), and funding from the ANS Foundation (MHT). 


\section{AUTHOR CONTRIBUTIONS}

JBG and CBN conceived the idea and wrote the initial drafts. MHT wrote the final drafts and supplementary materials with input from the other co-authors.

\section{COMPETING INTERESTS}

MHT has created rating scales to retrospectively assess type and timing of exposure to $C M$ [16] but there is no financial conflict as he has placed these scales into the public domain. MHT has also received research or consulting fees (last 12 months) from the $\mathrm{NIH}$, Interactive Metronome $\mathrm{T}^{\mathrm{TM}}$, Brain Balance Centers ${ }^{\mathrm{T}} \mathrm{M}$, the ANS Foundation, and MindLight ${ }^{\mathrm{T} w}$. MHT is on the Scientific Advisory Board for the Juvenile Bipolar Research Foundation and member of the Board of Children, Youth and Families at the National Academies of Sciences, Engineering and Medicine and a member of the Board of Directors of the Trauma Research Foundation and the Kahn Family Foundation. MHT has been awarded 19 US Patents, none of which are relevant to this article. CBN has received grant support from the NIH. During the last 12 months, he has consulted to ANeuroTech (division of Anima BV), Signant Health, Sunovion Pharmaceuticals, Inc., Janssen Research \& Development LLC, Magstim, Inc., Navitor Pharmaceuticals, Inc., Intra-Cellular Therapies, Inc., EMA Wellness, Acadia Pharmaceuticals, Axsome, Sage, BioXcel Therapeutics, Silo Pharma, XW Pharma, Neuritek, Engrail Therapeutics, and Corcept Therapeutics Pharmaceuticals Company. CBN is a stockholder in Xhale, Seattle Genetics, Antares, BI Gen Holdings, Inc., Corcept Therapeutics Pharmaceuticals Company, and EMA Wellness; he is on the Scientific
Advisory Board for ANeuroTech (division of Anima BV), Brain and Behavior Research Foundation (BBRF), Anxiety and Depression Association of America (ADAA), Skyland Trail, Signant Health, Laureate Institute for Brain Research (LIBR), Inc., Magnolia CNS; and he is on the Board of Directors for Gratitude America, ADAA, and Xhale Smart, Inc. CBN holds two patents: Method and devices for transdermal delivery of lithium (US 6,375,990B1) and Method of assessing antidepressant drug therapy via transport inhibition of monoamine neurotransmitters by ex vivo assay (US 7,148,027B2). He is not a part of any Speakers Bureau. JBG has no potential conflicts of interest to disclose.

\section{ADDITIONAL INFORMATION}

Supplementary information The online version contains supplementary material available at https://doi.org/10.1038/s41380-021-01367-9.

Correspondence and requests for materials should be addressed to Charles B. Nemeroff.

Reprints and permission information is available at http://www.nature.com/ reprints

Publisher's note Springer Nature remains neutral with regard to jurisdictional claims in published maps and institutional affiliations. 